\title{
Claude Duchet, Dominique Pety, Philippe Régnier, Bibliographie du Dix-neuvième siècle, année 2002
}

\section{Ida Merello}

\section{Q OpenEdition}

1 Journals

\section{Edizione digitale}

URL: http://journals.openedition.org/studifrancesi/35042

DOI: 10.4000/studifrancesi.35042

ISSN: 2421-5856

\section{Editore}

Rosenberg \& Sellier

\section{Edizione cartacea}

Data di pubblicazione: 1 novembre 2005

Paginazione: 441

ISSN: 0039-2944

\section{Notizia bibliografica digitale}

Ida Merello, «Claude Duchet, Dominique Pety, Philippe Régnier, Bibliographie du Dix-neuvième siècle, année 2002», Studi Francesi [Online], 146 (XLIX | II) | 2005, online dal 30 novembre 2015, consultato il 19 avril 2021. URL: http://journals.openedition.org/studifrancesi/35042 ; DOI: https://doi.org/10.4000/ studifrancesi.35042

Questo documento è stato generato automaticamente il 19 avril 2021.

\section{(c) (1)}

Studi Francesi è distribuita con Licenza Creative Commons Attribuzione - Non commerciale - Non opere derivate 4.0 Internazionale. 


\title{
Claude Duchet, Dominique Pety, Philippe Régnier, Bibliographie du Dix-neuvième siècle, année 2002
}

\author{
Ida Merello
}

\section{NOTIZIA}

CLAUDE DUCHET, DOMINIQUE PETY, PHILIPPE RÉGNIER, Bibliographie du Dix-neuvième siècle, année 2002, Paris, Presses de la Sorbonne nouvelle, 2004, pp. 265.

1 Quinta pubblicazione della serie, la Bibliographie si presenta in veste editoriale rinnovata e ampliata nella sua panoramica per la crescita dei suoi collaboratori. Unica nel suo genere, la Bibliographie non pretende di render conto delle opere critiche relative a una sola disciplina, bensì agli studi che escono anno per anno sul XIX secolo (in senso lato, fino al 1914) in tutti i suoi aspetti letterari, storici, artistici, scientifici e relativamente a tutti i Paesi. La consultazione potrebbe risultare non agevole per lo specialista, favorendo invece il curioso che si lasci sedurre dalla ricchezza dei materiali proposti (suddivisi per edizioni di testi, opere, opere collettive e riviste) ma una rigorosa tripartizione degli indici (per nomi d'autore, nomi di critici, temi) soddisfa immediatamente qualsiasi esigenza. Le opere citate godono anche di due righe di presentazione e quelle ritenute più significative sono segnalate da una barra verticale a lato, che sostituisce la stella utilizzata in precedenza. Insomma, un'opera preziosa per chiunque. 